\title{
Multi-Feedstock Biodiesel Production from Esterification of Calophyllum inophyllum Oil, Castor Oil, Palm Oil, and Waste Cooking Oil
}

\author{
H. Hadiyanto ${ }^{1,2,3}$, Apsari Puspita Aini1 ${ }^{1,3}$, W. Widayat ${ }^{1}$, K. Kusmiyati ${ }^{4}$, Arief \\ Budiman $^{5}$, Achmad Rosyadi ${ }^{6}$
}

\author{
${ }^{1}$ Department of Chemical Engineering, Diponegoro University, Jl Prof. Soedharto, SH, Tembalang, Semarang 50275, Indonesia. \\ ${ }^{2}$ School of Postgraduate Studies, Diponegoro University, Jl Imam Bardjo, SH, Semarang 50275, Indonesia. \\ ${ }^{3}$ Center of Biomass and Renewable Energy (C-BIORE), Diponegoro University, Jl Prof. Soedharto, SH, Tembalang, Semarang 50275, Indonesia \\ ${ }^{4}$ Faculty of Engineering, Dian Nuswantoro University, Semarang, Indonesia \\ ${ }^{5}$ Department of Chemical Engineering, Gadjah Mada University, Yogyakarta, Indonesia \\ ${ }^{6}$ Department of Chemical Engineering, Sepuluh November Institute of Technology, Surabaya, Indonesia
}

\begin{abstract}
Biodiesel can be produced from various vegetable oils and animal fat. Abundant sources of vegetable oil in Indonesia, such as Calophyllum inophyllum, Ricinus communis, palm oil, and waste cooking oil, were used as raw materials. Multi-feedstock biodiesel was used to increase the flexibility operation of biodiesel production. This study was conducted to determine the effect of a combination of vegetable oils on biodiesel characteristics. Degumming and two steps of esterification were applied for high free fatty acid feedstock before trans-esterification in combination with other vegetable oils. Potassium hydroxide was used as a homogenous catalyst and methanol as another raw material. The acid value of C. inophyllum decreased from $54 \mathrm{mg} \mathrm{KOH} / \mathrm{gr}$ oil to $2.15 \mathrm{mg} \mathrm{KOH} / \mathrm{gr}$ oil after two steps of esterification. Biodiesel yield from multi-feedstock was $87.926 \%$ with a methanol-to-oil molar ratio of $6: 1$, temperature of $60{ }^{\circ} \mathrm{C}$, and catalyst of $1 \%$ wt. (O2020. CBIORE-IJRED. All rights reserved
\end{abstract}

Keywords: Multi-feedstock biodiesel, trans-esterification, Calophyllum inophyllum, palm oil, waste cooking oil.

Article History: Received: Oct 19, 2019; Revised: December 22, 2019; Accepted: January 21, 2020; Available online: February 15, 2020

How to Cite This Article: Hadiyanto, H., Aini, A.P., Widayat, W., Kusmiyati, K., Budiman, A. and Rosyadi, A. (2020). Multi-Feedstock Biodiesel Production from Esterification of Calophyllum inophyllum Oil, Castor Oil, Palm Oil, and Waste Cooking Oil. International Journal of Renewable Energy Development, 9(1), 119-123

https://doi.org/10.14710/ijred.9.1.119-123

\section{Introduction}

With the depletion of petroleum reserves as the main source of fuel, many researchers have developed other sources that are renewable and sustainable to produce biofuel. Biofuel consists of bio-gasoline, bio-avtur, and biodiesel. In 2017, the United States and Brazil were the largest biodiesel producers in the world, with a total production of 6 and 4.3 billion L, respectively, followed by Germany (3.5 billion), Argentina (3.3 billion), Indonesia (2.5 billion), France (2.3 billion), Thailand (1.4 billion), and China (1 billion) (Wang 2018). In Indonesia, the contribution of renewable energy sources in the national energy mix in 2025 is targeted to be $25 \%$, and bioenergy including biodiesel is expected to contribute $5 \%$ to those energy needs. Biodiesel is produced by converting vegetable oil and animal fat with methanol or ethanol through trans-esterification. Vegetable oils that are commonly used for biodiesel raw material are soybean oil, rapeseed oil, corn oil, palm oil, waste cooking oil, yellow grease, and castor oil (Gokdogan et al., 2015). Homogeneous catalysts, such as potassium hydroxide, and sodium hydroxide, were used as alkaline catalysts in trans-esterification, whereas hydrochloric acid, and sulfuric acid were used as acid catalysts in esterification. Although homogeneous catalysts could not be reused and require other separation processes after transesterification, they have been widely used worldwide. Meanwhile, heterogeneous catalysts are still being developed to achieve optimal catalytic performance with high-selectivity biodiesel.

In previous research, biodiesel has been used a single oil feedstock. It depends on the type of vegetable oil used and the country's production and reduces the flexibility of operations. Not all countries have a large production of vegetable oils that can be used as feedstock for biodiesel. For example, soybean oil became the largest commodity used in America. However, it could not be applied as a major feedstock in Indonesia because it is classified as a food commodity. In addition, it is still imported from another country because its average production only fulfills $43 \%$ of soybean needs (Hadiyanto et al., 2018). Moreover, not all vegetable oils are 
available throughout the year. Thus, several vegetable oils used as feedstock (multi-feedstock) can be a better solution in the future.

This study aimed to determine the effect of mixture oils as a feedstock in biodiesel production. In consideration that biodiesel products are very dependent on the physical and chemical characteristics of the oil used, biodiesel from the oil mixture definitely shows a difference compared with single feedstock.

\section{Materials and Methods}

\subsection{Materials}

Calophyllum inophyllum oil was purchased from Kroya, Cilacap. Waste cooking oil was collected from family welfare education groups in Semarang. Palm Oil was purchased from Supermarket near Diponegoro University, Semarang. Ricinis communis oil or castor oil was purchased from CV. Indrasari, Semarang. The chemicals used for experiment and analysis were methanol (99\%, Merck), ethanol (absolute, Merck), potassium hydroxide (Merck), hydrogen sulfate $(96.1 \%$, Mallinckrodt Specialty Chemicals Co.), hydrogen phosphate (85.3\%, Bratachem), hydrogen chloride (37\%, Mallinckrodt Specialty Chemicals Co.), acetic acid glacial (Brightchem, Malaysia), chloroform (99\%, Merck), sodium thiosulfate pentahydrate (Merck), potassium Iodide (Merck), potassium dichromate (Merck), potato starch solution, and phenolphthalein.

The acid value of the raw materials was identified to determine the characteristic of the oil. Esterification and trans-esterification were applied to obtain raw materials with high free fatty acid (FFA), whereas direct trans-esterification was applied for low FFA value.

\subsection{Pre-treatment, Esterification, and Trans-esterification}

Degumming was carried out for $C$. inophyllum oil before esterification. The oil was heated until $75{ }^{\circ} \mathrm{C}$, and $1 \%$ wt $\mathrm{H}_{3} \mathrm{PO}_{4} 85 \%$ was added into the oil until $1 \mathrm{~h}$ reaction time. Then, the mixture was separated in the separating funnel during $24 \mathrm{~h}$ (Gokdogan et al., 2015). To extract gum from that, 1:3 oil-to-methanol ratio was added into the glass and centrifuged to produce pure oil.

Subsequently, esterification was performed under the following operation conditions: temperature of $\pm 60{ }^{\circ} \mathrm{C}$, reaction time of $2.5 \mathrm{~h}$, and oil-to-methanol ratio of $1: 2$. The esterification product containing excess methanol and alkyl ester was separated using a separating funnel for $24 \mathrm{~h}$. The alkyl ester was washed with distilled water $\left(60{ }^{\circ} \mathrm{O}\right)$ until neutral $\mathrm{pH}$ was reached. The alkyl ester was heated at $105{ }^{\circ} \mathrm{C}$ to remove the water content.

The product from esterification was subjected to trans-esterification. The operation conditions were temperature of $\pm 60{ }^{\circ} \mathrm{C}$, reaction time of $2.5 \mathrm{~h}$, and oil-to methanol molar ratio of 1:6. In trans-esterification, another oil such as castor oil, palm oil, and waste cooking oil were mixed with $C$. inophyllum oil produced from esterification. The product was separated using a separating funnel for $24 \mathrm{~h}$ until it formed two layers. The upper layer containing fatty acid methyl ester was washed with the same method in previous process. The side product glycerol was appeared in the bottom layer.

\subsection{Analytical methods}

Fatty acid methyl ester (FAME) was analyzed by gas chromatography mass spectrometry (GC-MS) to identify the type of FAME that results from the transesterification process. FFA value, saponification value, iodine value, total, and free glycerol, density, viscosity, and cetane number were also analyzed in accordance with ASTM D6751:

$$
\text { FAME (\% mass })=\frac{100\left(A_{s}-A_{a}-18.27 G_{t t l}\right)}{A_{s}}
$$
where,

As : saponification value $(\mathrm{mg} / \mathrm{g})$

Aa $\quad$ : acid value $(\mathrm{mg} / \mathrm{g})$

Gttl : total glycerol in biodiesel product (\% mass)

$$
\text { Yield }=\frac{\text { biodiesel }(g r)}{\text { oil }(g r)} \times \% \text { FAME }
$$

\section{Results and Discussion}

Biodiesel from single feedstock and multi-feedstock was applied to determine the differences in physical and chemical characteristics. Several feedstocks used in this experiment include Ricinus communis, soybean oil, waste cooking oil, palm oil, and C. inophyllum. The measurement of acid value (mg $\mathrm{KOH} / \mathrm{gr}$ oil) was conducted before the experiment to ensure whether esterification or trans-esterification should be the first process in biodiesel production. Acid values of several raw materials are presented in Table 1. Castor oil, soybean oil, waste cooking oil, and coconut oil have acid values below 2 , but the acid value of $C$. inophyllum is higher than 2. Thus, it needs pre-treatment and esterification before trans-esterification.

Table 1

Chemical composition of raw materials

\begin{tabular}{lccccc}
\multicolumn{1}{c}{ Characteristic } & \multicolumn{5}{c}{ Raw material } \\
\cline { 2 - 6 } & CO & SO & WCO & PO & CIO \\
\hline Acid value (mg KOH/gr oil) & 1.21 & 1.85 & 3.199 & 0.6 & 54 \\
Density $40^{\circ} \mathrm{C}(\mathrm{kg} / \mathrm{L})$ & 935.82 & 910.56 & 903 & 931.93 & 948.72 \\
Kinematic viscosity (mm/s) & 1003.39 & 56.12 & 47.176 & 78.87 & 55.86 \\
\hline CO: castor oil, SO: soybean oil, WCO: waste cooking oil, PO: palm oil, CIO: Callophylum inophyllum oil
\end{tabular}

Vegetable oils with low acid values can directly undergo trans-esterification using potassium hydroxide as a base catalyst. The characteristic of the biodiesel is presented in Table 2.
The yield of biodiesel from several feedstock exceeded $60 \%$. The highest yield of biodiesel (90.875\%) was achieved using palm oil as feedstock. Biodiesel was also produced from palm oil in previous research (El-Araby et 
al., 2018) using potassium hydroxide as a catalyst. The density and viscosity of palm oil methyl ester in this experiment were similar to those in the study by ElAraby (2018) with $877 \mathrm{~kg} / \mathrm{L}$ and $4.56 \mathrm{~mm}^{2} / \mathrm{s}$ and Ali et al. (2013) with $876 \mathrm{~kg} / \mathrm{m}^{3}$ and $4.76 \mathrm{~mm}^{2} / \mathrm{s}$, respectively.
Meanwhile, the chemical composition of palm oil methyl ester using GC-MS mostly consisted of $40.2 \%$ palmitic acid methyl ester and $42.4 \%$ oleic acid methyl ester.

Table 2

Chemical characteristic of biodiesel

\begin{tabular}{lrrrrr}
\hline \multicolumn{1}{c}{ Characteristic } & \multicolumn{5}{c}{ Biodiesel } \\
\cline { 2 - 6 } & \multicolumn{1}{c}{ CO } & \multicolumn{1}{c}{ SO } & WCO & \multicolumn{1}{c}{ PO } & \multicolumn{1}{c}{ CIO } \\
\hline Acid value (mg KOH/gr oil) & 0.437 & 0.715 & 0.984 & 0.561 & 1.091 \\
Saponification value (mgKOH/gr oil) & 142.263 & 143.67 & 156.14 & 198.97 & 186.53 \\
Free glycerol (\%-mass) & 0.054 & 0.174 & 0.074 & 0.037 & 0.032 \\
Total glycerol (\%-mass) & 0.354 & 0.362 & 0.166 & 0.261 & 0.147 \\
Bound glycerol (\%-mass) & 0.3 & 0.188 & 0.092 & 0.224 & 0.115 \\
Density at 40 ${ }^{\circ} \mathrm{C}$ (kg/L) & 916 & 872 & 862 & 844 & 865 \\
Viscosity(mm $/ \mathrm{s}$ ) & 29.91 & 6.41 & 7.076 & 4.135 & 6.78 \\
Iodine value & 90.416 & 92.796 & 88.037 & 58.691 & 95.968 \\
FAME (\%-mass) & 95.145 & 94.899 & 97.427 & 97.323 & 97.975 \\
Yield (\%) & 69.919 & 76.736 & 90.293 & 90.875 & 81.542 \\
\hline \multicolumn{1}{c}{ CO: castor oil, SO: soybean oil, WCO: waste cooking oil, PO: palm oil, CIO: Callophylum inophyllum oil }
\end{tabular}

The production of biodiesel from other feedstocks, such as castor oil, soybean oil, and waste cooking oil, has been conducted by many previous researchers (Valente et al., 2011; Ganjehkaviri, 2018; Aworanti et al., 2012; Doll et al., 2008; Doll et al., 2010). Table 1 shows that biodiesel from soybean oil and palm oil provides good results. However, both of them are considered food commodities. Therefore, all of the stocks cannot be used for energy before food demand is fulfilled.

Waste cooking oil became an alternative raw material because it includes untapped waste in
Indonesia. Slight differences in FAME between waste cooking oil and palm oil indicated that fatty acid hydrolysis in waste cooking oil did not occur frequently. However, the kinematic viscosity of waste cooking oil was higher than that pf palm oil. The characteristics of waste cooking oil (FFA, density, and water content) from different sources are different. It depends on utilization cooking oil in daily life. Thus, the measurement of raw material characteristic is the important step before trans-esterification.

Table 3

Chemical characteristic of multi-feedstock biodiesel

\begin{tabular}{lccc}
\multicolumn{1}{c}{ Biodiesel characterization } & \multicolumn{3}{c}{ Biodiesel } \\
\cline { 2 - 4 } & A & B & C \\
\hline Acid value (mg KOH/gr oil) & 0.898 & 0.890 & 1.110 \\
Saponification value (mgKOH/gr oil) & 180.92 & 189.30 & 173.91 \\
Free glycerol (\%-mass) & 0.026 & 0.030 & 0.047 \\
Total glycerol (\%-mass) & 0.520 & 0.431 & 0.344 \\
Bound glycerol (\%-mass) & 0.494 & 0.401 & 0.297 \\
Density (40C) & 910.73 & 875 & 904 \\
Viscosity (mm2/s) & 7.49 & 8.36 & 7.440 \\
Iodine value & 93.589 & 95.175 & 92.796 \\
FAME (\%-mass) & 99.46 & 99.51 & 99.630 \\
Yield & 86.891 & 87.924 & 86.60 \\
Cetane number & 56.600 & 57.591 & 57.843 \\
\hline
\end{tabular}

O: castor oil, SO: soybean oil, CRO: corn oil, WCO: waste cooking oil, PO: palm oil, CIO: Calophyllum inophyllum oil

A: CO, SO, CRO, PO, WCO; B : CO, PO, WCO, CIO; C : CIO Biodiesel and Biodiesel from CO, SO, PO, WCO

Another resource in Indonesia that could be utilized as biodiesel feedstock is C. inophyllum. Given that it achieved the highest acid value among the other resources, C. inophyllum needs two steps of pretreatment before trans-esterification. First, degumming was applied to $C$. inophyllum oil. Degumming was 
employed to remove gum and other components in oil to produce oil without gum or straight vegetable oil. After degumming, the acid value of $C$. inophyllum decreased from 54 to 37.59. Other experiments conducted by Andyna (2009) showed that oil color changes from dark green to brown-orange after degumming, indicating that the gum in the oil is completely removed. Second process was esterification. Esterification is a reversible reaction between carboxylic acid and alcohol to form ester using an acid catalyst. In the present study, we used sulfuric acid as an acid catalyst. Previous research that conducted esterification of fatty acid mixture reported that sulfuric acid and methane sulfonic acid as acid catalysts result in the highest conversion (higher than $90 \%$ during $1 \mathrm{~h}$ ) compared with another catalyst, such as phosphoric acid and trichloroacetic acid (Aranda et al., 2008). This result can be ascribed to the fact that sulfuric acid and methane sulfonic acid have higher acid strength than other catalysts. Another experiment also used sulfuric acid as a catalyst for the esterification of crude rubber seed oil before trans-esterification. Many researchers choose sulfuric acid because of its high catalytic activity and low cost (Thaiyasuit et al., 2012).

The acid value of $C$. inophyllum oil reduced from $37.59 \mathrm{mg} \quad \mathrm{KOH} / \mathrm{gr}$ to $4.4 \mathrm{mg} \mathrm{KOH} / \mathrm{gr}$ oil after esterification. Two steps of esterification were applied in this experiment to reduce acid value. In each step, $6 \% \mathrm{wt}$ oil and $3 \% \mathrm{wt}$ oil of sulfuric acid were added into the reactor with methanol-to-oil ratio of $1: 2$ volume at $60{ }^{\circ} \mathrm{C}$. The final result of acid value in the second step of esterification was $2.15 \mathrm{mg} \mathrm{KOH} / \mathrm{gr}$ oil. Andyna (2009) reported that Sudradjat (2008) conducted esterification with $6 \%$ hydrochloric acid as a catalyst and a methanoland-FFA ratio of 20:1 for $1 \mathrm{~h}$. The acid value can reduce to $4.7 \%$ after esterification.

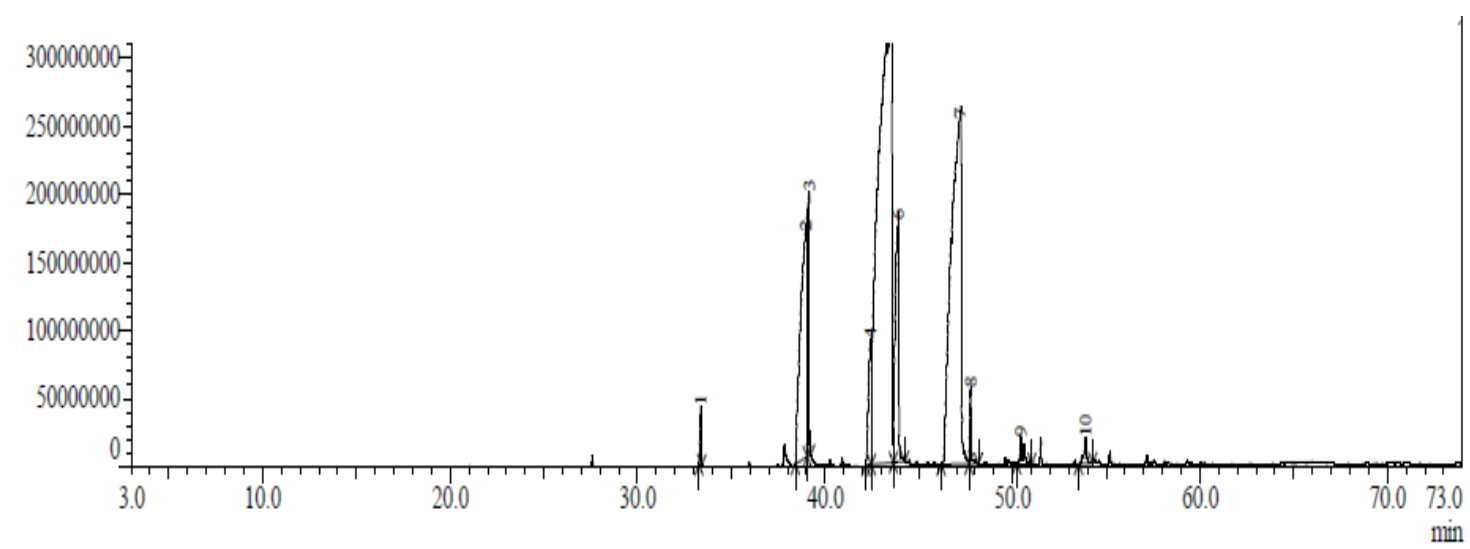

Figure 1. GC-MS Chromatogram of multi-feedstock biodiesel

The last process was trans-esterification, which was conducted using potassium hydroxide as a catalyst under a temperature of $60{ }^{\circ} \mathrm{C}$, a methanol-to-oil molar ratio of $1: 6$, and reaction time of $2 \mathrm{~h}$. The yield of $C$. inophyllum was $81.542 \%$ with a FAME percentage was 97.975\%-mass. The acid value, saponification, and iodine value of biodiesel were lower than those of $C$. inophyllum in the study by Andyna (2009). However, the kinematic viscosity in this work was greater than that in the study by Andyna (2009) and exceeded the limit standard. Valente et al. (2011) reported that high viscosity causes slow biodiesel flow, which could hamper the degree of atomization of fuel in the combustion chamber.

Three types of experiment were carried out to determine the flexibility of feedstock to produce biodiesel. The yield and other characteristics of multi-feedstock biodiesel are shown in Table 3. Experiment A used CO, $\mathrm{SO}, \mathrm{CRO}, \mathrm{WCO}$, and $\mathrm{PO}$, which have acid values below two; thus, only trans-esterification was employed in this experiment. Experiment B used CO, PO, WCO, and CIO. In consideration that the acid value of CIO was high, it initially needed degumming and esterification. Then, it was mixed with other feedstocks and subjected to transesterification. Experiment $\mathrm{C}$ was a mixture of biodiesel A with biodiesel CIO. The GC-MS chromatogram of the experiment is shown in Figure 1, and the percentage of FAME from GC is presented in Table 4.
Table 4.

Fatty acid methyl ester of multi-feedstock biodiesel

\begin{tabular}{lccc} 
FAME & A & B & C \\
\hline Myristate (C14:0), & 0.47 & 0.47 & 0.35 \\
Palmitate (C16:0), & 15.57 & 11.98 & 14.77 \\
Palmitoleate (C16:1) & 1.21 & 0 & 0.66 \\
Stearate (C18:0) & 4.45 & 6.68 & 9.19 \\
Oleate(C18:1 & 73.64 & 72.91 & 70.82 \\
Linoleate (C18:2), & 4.06 & 2.69 & 3.28 \\
Arachidate (C20:0) & 0.6 & 0.77 & 0.93
\end{tabular}

As shown in Table 3, the multi-feedstock did not considerably affect the acid value, saponification value, iodine value, \% FAME, yield biodiesel, and cetane number. However, differences in density and viscosity were found. Acid values in all of the experiments were higher than the standard $(0.5 \mathrm{mgKOH} / \mathrm{gr})$ because one of the vegetables used in the experiment has high acid value, although it has been reduced through esterification. High acid value can cause corrosion in the engine. Jahirul et al. (2015) revealed that besides corrosion, it also causes higher level degradation of lubricant. Other parameters, such as cetane number, are also important to observe. The cetane number of biodiesel 
in this work was calculated based on the composition of FAME in biodiesel as previously described by Tong et al. (2011). The combination of methyl ester A, B, and C can be observed in Table 4. Unsaturated methyl ester and oleate methyl ester (C18:1) had the highest composition $(\sim 70 \%)$. It originated from the percentage of oleic acid in palm oil (41.40\%), castor oil (29.90\%), and CIO (37.57\%). The cetane number in the three experiments was higher than the minimum standard of 51. Cetane number represents the ignition delay time in engine. Higher cetane number indicates performance of engine. Cetane number decreases with more unsaturated and shorter chains in the biodiesel (Angelovic, 2014). Further improvement was included in the concentration of catalyst in esterification and trans-esterification, reaction time, and methanol-to-oil ratio to obtain the best quality of biodiesel.

\section{Conclusion}

The highest yield of single feedstock biodiesel from palm oil achieved $90.87 \%$. As another alternative source, aside from waste cooking oil, C. inophyllum, could be converted to biodiesel with a three-step process, including degumming, esterification, and trans-esterification, with acid value reduced from 54 to $1.09 \mathrm{mg} \mathrm{KOH} / \mathrm{gr}$ in the final product. The highest yield of multi-feedstock biodiesel in this work achieved 87.92\%. The characteristics of biodiesel from the multi-feedstock, such as the percentage of FAME, acid value, saponification value, iodine, and cetane number, showed no significant effects compared with the single feedstock, although the acid value, density, and viscosity were still higher than the standard. Further improvement during esterification is needed to reduce the acid value of $C$. inophyllum. The composition of oil must be designed properly to achieve density and viscosity in accordance with the standard.

\section{Acknowledgement}

The authors would like to express their appreciation for the support from the Ministry of Research, Technology and Higher Education (KEMENRISTEKDIKTI) through Hibah Konsorsium Riset Unggulan Perguruan Tinggi (KRUPT) No 451-01/UN-7.P4.3/PP/2019 under title of grant: Production of multi-feedstock biodiesel with high flexibility to support national energy security.

\section{References}

Andyna, J.Y., Nurin. (2009). Pembuatan Biodiesel dari Minyak Biji Nyamplung (Calophyllum inophylum L). Bandung: FMIPA Institut Teknologi Bandung.

Angelovic, M., Zdenko Tkac \& Juraj Jablonicky. 2014. Determination Model for Cetane Number of Biodiesel at
Different Fatty Acid Composition: A Review. Scientific Papers : Animal Science and Biotechnologies. 47 (1).

Ali, E.N., Tay, C.I. (2013). Characterization of biodiesel produced from palm oil via base catalyzed transesterification. Procedia Eng. 53, 7-12.

Aranda, D. A. G., Santos, R.T.P. Tapanes, N.C.O., Ramos, A.L.D., Antunes, O.A.C. 2008. Acid-Catalyzed Homogeneous Esterification Reaction for Biodiesel Production from Palm Fatty Acids. Catalysis Letters. 122:20-25.

Aworanti, O.A., Agarry, S.E., Ajani, A.O. 2012. A laboratory Study of the Effect of Temperature on Densities and Viscosities of Binary and Ternary Blends of Soybean Oil, Soybean Biodiesel and Petroleum Diesel Oil. Advances in Chemical Engineering and Science, 2, 444-452.

Bladt, D., Murray, S., Gitch, B., Trout, H., and Liberko, C., 2010. Acid-Catalyzed Preparation of Biodiesel from Waste Vegetable Oil: An Experiment for the Undergraduate Organic Chemistry Laboratory. Journal of Chemical Education. 88, 2.

Doll, K.M., Sharma, B.K., Suarez, P.A.Z., Erhan, S.Z. 2008. Comparing Biofuels Obtained from pyrolysis of soybean oil or soapstock, with traditional soybean biodiesel: density, kinematic viscosity, and surface tensions. Energy \& Fuels, 22, 2061-2066.

El-Araby, R., Amin, A., El Morsi, A.K., El-Ibiari, N.N., ElDiwani, G.I. Study on the characteristics of palm oilbiodiesel-diesel fuel blend. Egyptian Journal of Petroleum. Vol 27, 2. 2018.

Ganjehkaviri, A., Jaafar, M.N.M., Hosseini, S. E., and Musthaa, A. B. 2016. Performance Evaluation of Palm Oil-Based Biodiesel Combustion in an Oil Burner. Energies, 9, 97.

Gokdogan, O., Eryilmaz, T., and Yesilyurt, M.K, Thermophysical Properties of Castor Oil (Ricinus Communis L.) Biodiesel and Its Blends, Journal of Oil, Gas, and Alternative Energy Sources 6, 1, 2015.

Hadiyanto, H., Inaya Yuliandaru, I., Hapsari, R.(2018). Production of Biodiesel from Mixed Waste Cooking and Castor Oil. MATEC Web of Conferences 156, 03056

Jahirul, M.I., Brown, M.J., W. Senadeera, W., Ashwat, N., Rasul, M.G., Rahman, M.M., Hossain, F.M., Moghaddam, L., Islam, M.A., O'Hara, I.M. Physiochemical assessment of beauty leaf (Calophyllum inophyllum) as second-generation biodiesel feedstock. Energy Report, 1,204-215

Thaiyasuit, P., Pianthong, K., and Worapun, I. 2012. Acid Esterification-Alkaline Transesterification Process for Methyl Ester Production from Crude Rubber Seed Oil. Journal of Oleo Sci. 61 (2) 81-88 (2012).

Tong, D., Hu, C., Jiang K., Li, Y. 2011. Cetane Number Prediction of Biodiesel from the Composition of Fatty Acid Methyl Ester. J. Am Oil Chem Soc. 88: 415-423.

Valente, O.S., Pasa, V.M.D., Belchior, C.R.P., Sodre, J.R. 2011. Physical-chemical properties of waste cooking oil biodiesel and castor oil biodiesel blends. Fuel. 90.

Wang, T. (2018). Global biodiesel production by country 2017, Statisca, 2018

This article is an extended version of a paper presented at International Conference of Process and Product Engineering (ICCPPE 2019) held on Sept 25, 2019. The article has been reviewed by journal peer-reviewers including complete proofs.

C 2020. This article is an open access article distributed under the terms and conditions of the Creative Commons Attribution (CC BY) license (http://creativecommons.org/licenses/by/4.0/) 